\section{Uproar at Oxford as suspended professor returns to work}

\section{London}

Two staff members have begun grievance procedures against the University of Oxford over its handling of their complaints against Roy Anderson, the Linacre professor of zoology.

They say that Anderson's apologies to staff who had accused him of offensive behaviour are "unsatisfactory". They have protested at the university's decision last week to let him resume teaching and research.

Anderson remains suspended as director of the Wellcome Trust Centre for Epidemiology of Infectious Diseases, as investigations continue into alleged business irregularities (see Nature 403, $695 ; 2000$ ). Solicitors for zoologists Sunetra Gupta and Karen Day, whose complaints initiated the disciplinary proceedings, say that Anderson's apology has not removed a "sexual slur" against Gupta. It is alleged that Anderson had claimed she had an improper relationship with the head of the university's department of zoology, Paul Harvey.

The solicitors say that a statement from the university made "no reference

to the fact that
complaints had
been upheld and
that Professor
Anderson has been
disciplined as a
result".
The university
says that written
apologies have
been sent to all
concerned, but
Harvey says that
he has not received

one. "I want a retraction [of the sexual slur], which I have not yet had," he adds.

News of Anderson's reinstatement was met by uproar at a meeting of senior staff which passed a unanimous vote of no confidence in him. Twenty-five zoology faculty members have sent a letter of protest to the vice-chancellor over the reinstatement of Anderson without their acceptance. Some staff members say he should be banned from appointment committees and that he should not be reinstated before financial and management audits are completed.

Anderson's lawyers said this week: "Disciplinary matters have come to an end, the university has issued a statement and Professor Anderson has signed up to that statement." Natasha Loder

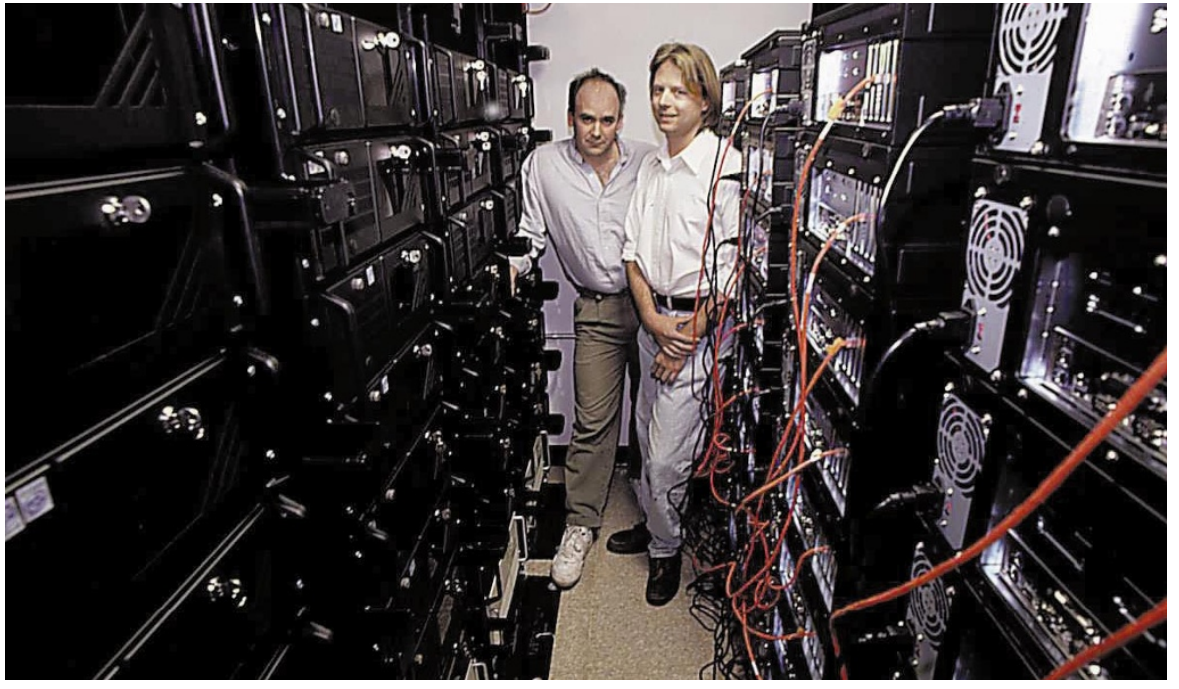

Parallel evolution: Wheeler (left) and Janies survey their handmade, 129-box phylogeny-cruncher.

\title{
Homegrown computer roots out phylogenetic networks
}

London

If Ward Wheeler and Dan Janies suffer any computer glitches, they won't need to rely on the IT helpline. These two systematic biologists, based at the American Museum of Natural History (AMNH) in New York, should know exactly how to fix their powerful parallel computing system — they built it themselves from scratch.

Their machine is a testament to what can be achieved with some imagination, a 'can do' attitude, and a truckload of parts from your local Radio Shack. And it is already being used to slash the time needed to find the most likely phylogeny describing the evolutionary relationships between groups of organisms, or taxa.

Systematists like Wheeler and Janies view phylogenies as 'unrooted' networks. 'Rooting' the network to a putative common ancestor, producing the familiar textbook evolutionary tree, comes later.

Identifying the most plausible unrooted network can present a formidable computational challenge. There is just one unrooted network that expresses the relationship among three taxa. But after that, the numbers go up rapidly: with four taxa, there are three possible solutions; with five taxa, there are 15; with 10 taxa, there are 2,027,025, and with 20 there are around $2.21 \times 10^{20}$.

Rather than test every possible permutation, systematists use algorithms that select the ones that look most likely and ignore the majority - a compromise, perhaps, but one that produces solutions in less than a human lifetime. But even so, you need a powerful computer to crack difficult phylogenetic problems in hours, rather than years.

Wheeler and Janies have given themselves a state-of-the-art computer for a fraction of the usual price. The secret is a massively parallel design, using off-the-shelf components, a freeware operating system, and homegrown phylogenetic software. The hardware is a stack of 129 boxes each fitted with a hard drive, a pair of 500-MHz Pentium III processors and $512 \mathrm{Mb}$ of RAM, connected over a 100-Mbit switched network. One machine acts as the master that controls all the others.

"We made the thing from bare bones," says Wheeler. When they placed the order for the parts, he says, the incredulous electronics supplier thought that Wheeler and Janies ran their own computer shop. Bolting the bits together took a week and a half.

Fitting out a suitable room with air conditioning and switching cost US\$300,000; the hardware came to another US $\$ 300,000$. The operating system was free - the machine uses Linux, a freeware system similar to Unix. Funds came from NASA, the AMNH and the City of New York.

Wheeler is currently using the system to crunch through a 130-taxon insect database that combines data on morphology and molecular biology. There are $10^{154}$ possible networks for a data set this size. But the new system allows unprecedentedly fast and aggressive search strategies. "We found better solutions in hours than we had found in months of searching before," says Wheeler.

The system can be accessed remotely, and is being used by an increasing roster of collaborators working on a variety of problems. The homegrown parallel-processing software used by Wheeler and his colleagues can be downloaded from the Internet, at $\mathrm{ftp}$. amnh.org/pub/molecular/poy and at $\mathrm{ftp}$. amnh.org/pub/molecular.malign. Henry Gee 